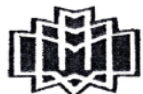 \\ Iranian Journal of Applied Linguistics $(I J A L)$
}

Vol. 19, No. 2, September 2016, 33-60

\section{A Comparison of Thematic Choices and Thematic Progression Patterns in the Research Articles of Well-established and Emerging Disciplines}

Esmat Babaii*, Kharazmi University, Tehran, Iran

Mahmood Reza Atai, Kharazmi University, Tehran, Iran

Leila Shoja, Kharazmi University, Tehran, Iran

\begin{abstract}
Several studies have employed the theme-rheme construct to examine the generic profile of research articles (RAs). However, they have mostly focused on the subject matter and nature of disciplines, and other disciplinary characteristics as contextual factors which can impact the genre realization have not been considered in the discourse analysis research. This work, therefore, investigates thematic choices and thematic progression patterns in the RA in relation to the status of disciplines as well-established or emerging fields. To this end, a corpus of 240 RAs of mechanical engineering, biomedical engineering, horticulture, and environmental science were analyzed using Halliday's (1994) framework of thematicity and McCabe's (1999) model of thematic progression (TP). The results showed significant differences in the distributions of unmarked and marked themes as well as the patterns of thematic progression between the well-established and emerging disciplines. Based on the findings of this study, we suggest further consideration of the status of disciplines in discourse studies which can serve disciplinary research and contribute to the body of research on science.
\end{abstract}

Key words: Thematicity; Thematic progression (TP); Research article (RA); Well-established disciplines; Emerging disciplines

\section{Article Information:}

Received: 30 January $2016 \quad$ Revised: 28 July $2016 \quad$ Accepted: 12 August 2016

Corresponding author: Department of Foreign Languages, Kharazmi University, Tehran,

Iran_Email address: babai@khu.ac.ir 


\section{Introduction}

Advanced academic literacy which is comprised of both knowledge of different aspects of academic written discourse and knowledge of English used in different academic disciplinary communities is essential for producing appropriate and successful academic texts (Ferenz, 2005). Having gone through performing "knowledge-telling" tasks and creating texts in postgraduate courses, students are mostly required to embark on more intricate and advanced tasks of "knowledgetransforming", in which they have the opportunity to produce new knowledge. Reaching this level of literacy, students can actively participate in their respective disciplinary communities through writing, presenting, and publishing papers (Tardy, 2005, p. 325). So, in addition to having school-based expertise -- content knowledge of a field--, students need to develop scholarly expertise which involves the knowledge of disciplinary rhetorical practices since it is this latter type of expertise that underlies their membership in disciplinary communities and makes their knowledge-production activities and claims relevant (Geisler, 1994, as cited in Peters, 2011).

This is where English-medium publications come into play because they give multilingual writers the opportunity to present their research to a wider audience and are part of the reward and promotion systems of academic institutions (Lillis \& Curry, 2006; Polo \& Varela, 2009). A large body of research on academic literacy, therefore, has been conducted to examine both discursive and non-discursive components essential to accomplishing publication in English to inform both the teaching profession and the academic communities. Some studies have focused on the practices and experiences (e.g. Ammon, 2001; Canagarajah, 2002; Curry and Lillis, 2010) and some on the linguistic and rhetorical resources (e.g. Burgess, 2002; Duszak, 1997; Flowerdew, 2001; Uzuner, 2008).

As linguistic and textual features are among the key elements of academic literacy, they have been explored through different analytic approaches including discourse analysis. In fact, to tackle a number of issues like improving access to the academic communities for writers and overcoming the barriers to researchers

publishing their works, discourse analysts have explored and described macro 
structures such as the expert genres students must learn to read and write (e.g. the scientific research article, the abstract) and the genres students must produce in their academic career (e.g. the master's thesis) as well as these genres' linguistic and rhetorical features.

One of these important features is cohesion. As an element of textual competence in Bachman's (1990) model of communicative competence, cohesion "refers to the linguistic devices by which the speaker can signal the experiential and interpersonal coherence of the text -- and is thus a textual phenomenon" (Thompson, 2004, p. 179). Writing in an academic environment, the authors aim to produce texts that are cohesive and coherent in order to develop successful communication within the academic community. However, achieving cohesion in writing is not always a straightforward and simple undertaking. According to Halliday (1993, as cited in Aktas \& Cortes, 2008), cohesion has a special significance in written scientific discourse as there are "semantic discontinuity" cases when "writers make semantic leaps, across which the reader is expected to follow them in order to reach a required conclusion" (p. 82). Thus, the analysis of various cohesive devices and their use has attracted many researchers and language teachers involved in the study and instruction of academic writing (e.g. Aktas \& Cortes, 2008; Connor, 1984; Hinkel, 2001; Lei, 2012; Nesi \& Basturkmen, 2006, to name a few).

One of the devices for achieving cohesion in writing is thematicity, that is, "the structuring of the clause itself -- the order in which elements appear in the clause" (Thompson, 2004, p. 142). As a part of the organizational structure of texts, thematicity can help students shift from sentence-oriented writing to text-oriented writing in order to communicate their goals effectively as suggested by Thornbury (1999). Thematicity is also of significance for genre analysis as thematic choices are partly influenced by the genre (Fries, 1995; Plum, 1988). As Brandt (1986, as cited in Vande Kopple, 1991) puts it, "[i]n its relevance to the moment-by-moment focus of a discourse, theme is especially pertinent to relating written texts to the contexts in which they were produced" (p. 98). Thus, investigations into thematic choices can yield valuable insights into the structure and functions of different genres in different academic communities. 
Research article (RA) as one of the, if not the most, important academic genres, is the primary means by which new scientific claims in most of the academic disciplines are presented, disseminated, and discussed. Because of its significance as an academic genre, over the past decades a number of studies have been conducted on thematicity in RAs of different disciplines. Such studies uncover disciplinary variations and other context-related differences and clarify the structure and practice of disciplinary communities as discourse communities and in turn help their members with understanding their mechanisms and gaining entry to them. This is extremely important because differences in the practices of discourse communities "influence both the preferred modes of communication in different disciplines and the rhetorical characteristics of genres that students are expected to manage in becoming competent members of the discourse community" (Bhatia, 2004, p. 36).

Studies on disciplinary communities also can contribute to the body of research on science and its evolution especially in the field of philosophy of science. The epistemological views which are concerned with the progression of science are also useful for explaining the emergence and development of disciplines as scientific units. They even can be put together to explain the latter. For example, Kuhn's paradigm shifts may result from Popper's scientific falsification, and when paradigm shifting occurs noticeably, new scientific disciplines may come into existence (Webster, 2012). The issues relating to the establishment and status of disciplines are worthy of research for both academic and financial-political reasons. The former concerns the nature of disciplines and in turn the subjects and content of teaching as well as the topics and methods of research while the latter relates to the way a discipline is recognized to receive funding from universities and institutions and in turn to be active in the processes of decision-making (Avison, 1997). Discussing the formation, evolution, and establishment of disciplines, researchers use terms like emerging, nascent, mature, established, and well-established. A large number of well-established disciplines that are currently included in universities' programs have been founded and established in the $19^{\text {th }}$ century and even few like theology, law and medicine before that (Strohmayer, 2014). Well-established disciplines enjoy well-established theories which are often 
proposed by key intellectual figures involved in the formation and development of the discipline. Such theories are used and referred to and can have value and appeal for centuries. This simultaneously results from and leads to the solidity and maturity of the disciplines (Trench \& Bucchi, 2010). But emerging disciplines, which mostly form because of major political, socioeconomic, and technological changes in society (Greaves, 2008), are young and need "conceptual and methodological clarification", and this is where the philosophy of science is needed (Gonzalez, 2013, p. 6).

So, while the status of disciplines as nascent or established disciplines is a key issue in the research on science, it had been left out of the investigation in discourse analyses which aim to contribute to the body of knowledge on the language of science. In fact, the status of disciplines has not been considered a potentially influential factor in the analyses. This work, therefore, was an attempt to address this research gap by studying thematicity in relation to the status of the disciplines.

At the time of our analysis, most discourse analysis research has been done on different sections of RAs rather than full-length RAs. Therefore, adopting Systemic Functional Linguistic theory of language, this study investigated thematic choices in full-length research articles. More specifically, the study was an attempt to see how authors have used Theme choices and thematic progression (TP) patterns in the research articles of the two well-established disciplines of mechanical engineering and horticulture and two emerging disciplines of biomedical engineering and environmental science to shed light on the language of science, the construct of discipline, and the profile of RA as a scientific genre.

This study was conducted based on two analytical frameworks. These frameworks are Halliday's $(1985,1994)$ model of thematicity and McCabe's (1999) model of thematic progression (TP) patterns. In the Halliday's (1994) framework, Theme is distinguished from Subject, Topic, and New concepts, and the grammatical Subject is not an obligatory element of Theme. To guide Theme analysis, Halliday states that Theme occupies the first position in the clause, and then to define its boundary, he proposes the principle of one and only one topical Theme in every clause. Topical (experiential) Theme is an element of the clause to 
which a Transitivity function, e.g. process or participant, can be assigned. The composition (simple or multiple) and status (unmarked or marked) of themes are also discussed. Here, the terms 'composition' and 'status' are borrowed from Thompson (2004) to present Halliday's illustration clearly. The latter concerns the existence of textual and/or interpersonal Themes.

Constituents that play cohesive roles but do not have interpersonal or experiential meanings are textual Themes when they precede the topical Theme. They are continuatives (e.g. well, oh), conjunctions (e.g. and, but), and conjunctive adjuncts (e.g. instead, in other words). Constituents to which a Mood label can be assigned are interpersonal Themes. These include finite verbal operator (when preceding the topical Theme), modal and comment adjuncts (e.g. certainly, fortunately) as well as vocatives (e.g. personal names).

Theme markedness concerns the relationship between the Mood and Theme structures of the clause, that is, how the functional roles of constituents in a Theme analysis conflate with their functional roles in the Mood structure. A Theme is unmarked when Theme conflates with the Mood structure constituent that typically occurs in first position in clauses of that Mood type. Otherwise, it is marked.

The second framework used in this study was McCabe's (1999) model of thematic progression. As a revised version of Daneš's (1974) model, it includes four patterns of simple linear, constant Theme, split Theme, and split Rheme. In the Simple Linear pattern, the Rheme of one clause becomes the Theme of subsequent clause; in the Constant Theme progression the same Theme appears in a series of clauses which have different Rhemes; in the split Rheme pattern, the Rheme of a clause contains two ideas which are developed in the Themes of subsequent clauses, and in the split Theme pattern, the Theme of a clause has two or more ideas which are picked up in the Themes of subsequent clauses. Those themes which do not fit into the progression patterns are called peripheral themes.

As mentioned before, the current study aimed at demonstrating how authors choose Theme and develop thematic patterns and whether these choicesare related to the status of disciplines. Thus, the following research questions were formulated: 
1. Is there any significant difference in the Theme status between the wellestablished disciplines of mechanical engineering and horticulture and the emerging disciplines of biomedical engineering and environmental science?

2. Is there any significant difference in the Theme composition between the wellestablished disciplines of mechanical engineering and horticulture and the emerging disciplines of biomedical engineering and environmental science?

3. Is there any significant difference in the thematic progression patterns between the well-established disciplines of mechanical engineering and horticulture and the emerging disciplines of biomedical engineering and environmental science?

\section{Method}

\subsection{Corpus}

The corpus of this study consisted of 240 RAs from four disciplines of mechanical engineering, biomedical engineering, horticulture, and environmental science published in the time period of 2005-2015. Based on Biglan's (1973) taxonomy of academic disciplines, one of the most well-established schemes for classifying disciplines, all disciplines are hard applied sciences. The RAs of each discipline were selected from four leading and prominent peer-reviewed journals chosen based on their impact factors as well as the complementary factor targeted by SJR. We sampled the RAs through a systematic random sampling as follows: the third issue of each journal was picked out. Then, the third article was selected for inclusion in the final sample. If the third article was not a research article, for example a technical note, the minus or plus one formula was applied. As a result, the corpus was a representative sample of RAs from the four disciplines. Then, to have a uniform corpus across the fields and to control the possible effects of alternative article structures on theme choices and thematic patterns, the sampled articles were checked and those which did not comply with the IMRD model, the model of research articles proposed by Swales (1990, 2004), was excluded and replaced. Of course, as the existence of the four prototypical sections was key, one alternative form of IMRD where the method section follows the discussion section 
rather than the introduction section (Cargill \& O'Connor, 2009) was also considered acceptable.

\subsection{Procedure}

In studies on Thematization researchers choose different units of analysis like the clause, the orthographic sentence, and the T-unit (i.e., independent conjoinable clause complex) based on their corpus type and their purpose (McCabe, 1999). The optimal unit of analysis for this study was a T-unit because it is argued to be the most useful unit for theme analysis (Fries, 1994, as cited in Thompson, 2004), especially if researchers like us aim to analyze whole texts to find thematic patterns and methods of development (Fries \& Francis, 1992). A T-unit consists of an independent clause plus all of its hypotactically related clauses. When taking the Tunit as the unit of analysis, paratactically related clauses are analyzed for their independent Themes while in hypotactically related clauses only one Theme is analyzed for the whole clause complex. More specifically, if the dependent clause comes first, it is considered as the Theme of the entire clause complex, but if the independent clause comes first, its Theme is taken to be the Theme and the rest of the clause plus subsequent dependent clauses form the Rheme (McCabe, 1999).

Having chosen the unit of analysis, in the first phase of this research we adopted Halliday' (1994) model of thematization to identify the themes and rhemes of the T-units and also their status and composition. Then, in the second phase of the analysis, McCabe's (1999) model of thematic progression was employed to find the patterns formed between the themes and rhemes of the T-units. It should be remembered that a T-unit can and may participate in more than one thematic pattern. Following McCabe (1999), gaps of more than three T-units were not considered as parts of the thematic progression or chains.

To investigate the null hypotheses of the study formulated for the research questions, the raw data were transformed into adjusted data since the total number of T-units varied in the RAs of each discipline, and using IBM SPSS 22, three statistical tests of chi-square were run. 


\section{Results}

\subsection{Theme Categories, Status, and Composition}

The adjusted frequencies of theme choices in the RAs of the four disciplines are presented in ten categories including subject, complement, adjunct, dependent clause, verb, predicated theme, thematic equative, extraposition, there (existential), and wh-word (interrogative) in Table 1.

Table 1

Adjusted frequencies of theme categories in the RAs (per 10000 T-units)

\begin{tabular}{|c|c|c|c|c|c|c|c|c|c|c|}
\hline & subject & $\begin{array}{l}\text { adju } \\
\text { nct }\end{array}$ & $\begin{array}{l}\text { comp } \\
\text { l. }\end{array}$ & $\begin{array}{l}\text { dep. } \\
\text { clause }\end{array}$ & verb & $\begin{array}{l}\text { predi } \\
\text { ct. } \\
\text { theme }\end{array}$ & $\begin{array}{l}\text { them. } \\
\text { equa. }\end{array}$ & $\begin{array}{l}\text { extra } \\
\text { p. }\end{array}$ & $\begin{array}{l}\text { Ther } \\
\text { e }\end{array}$ & $\begin{array}{l}\text { Wh- } \\
\text { wor } \\
\text { d }\end{array}$ \\
\hline $\begin{array}{l}\text { Mechanical } \\
\text { engineering }\end{array}$ & $\begin{array}{c}6512.4 \\
3\end{array}$ & $\begin{array}{c}2285 . \\
58\end{array}$ & 9.49 & 551.93 & $\begin{array}{c}281.6 \\
6\end{array}$ & 4.43 & 3.16 & $\begin{array}{c}281.0 \\
3\end{array}$ & 65.19 & 5.06 \\
\hline $\begin{array}{l}\text { Biomedical } \\
\text { engineering }\end{array}$ & $\begin{array}{c}7402.7 \\
3\end{array}$ & $\begin{array}{c}1768 . \\
6\end{array}$ & 8.68 & 467.2 & $\begin{array}{c}117.5 \\
9\end{array}$ & 1.57 & 2.36 & $\begin{array}{c}157.8 \\
4 \\
\end{array}$ & 59.19 & 14.2 \\
\hline Horticulture & 7635.6 & $\begin{array}{c}1703 . \\
18\end{array}$ & 6.69 & 345.42 & 6.69 & 1.91 & .95 & $\begin{array}{c}190.4 \\
1\end{array}$ & 106.2 & 1.91 \\
\hline $\begin{array}{l}\text { Environmental } \\
\text { science }\end{array}$ & $\begin{array}{c}7662.9 \\
5\end{array}$ & $\begin{array}{c}1596 . \\
79\end{array}$ & 10.64 & 438.09 & 29.47 & 5.73 & 5.73 & $\begin{array}{c}134.2 \\
9\end{array}$ & $\begin{array}{c}104.8 \\
1\end{array}$ & $\begin{array}{c}11.4 \\
6\end{array}$ \\
\hline
\end{tabular}

As it is evident from the Table, in the RAs of all four disciplines, subject, adjunct, and, by a big margin, dependent clauses (in descending order) were the most frequently used theme categories. In the well-established disciplines of mechanical engineering and horticulture, thematic equative, predicated theme, and wh-word (in ascending order) were the least frequent categories while in the two emerging fields of biomedical engineering and environmental science, predicated theme, thematic equative, and complements (in ascending order) were the least common choices. As different functions for positive and negative existential clauses have been suggested by some researchers, we had a closer look at the content of existential (there) clauses. In general, existential clauses give new information, but negative existential clauses can also be used to react to the readers' expectations the writer anticipates (North, 2005). In the emerging 
disciplines, 83.4 percent of the existential clauses were positive and in the wellestablished disciplines this number was 71.3 percent. So, while in both wellestablished and emerging disciplines the number of positive existential clauses was larger than the number of negative clauses, comparatively in the well-established disciplines the difference of occurrence was smaller and negative there clauses were used far more frequently.

EXAMPLE 1: There are two serious problems (a low shoot regeneration ratio and few applicable receptors) in the genetic transformation systems of Rosa plants (Jiang et al. 2011).

Biological Planetarium 2014, 58(3), 427-435.

EXAMPLE 2: The other men ranged in age between 24 and 66 years (median 47). There was no requirement of a fasting period before blood sampling. Chemosphere 2006, 62, 333-336.

EXAMPLE 3: Examples of uncorrelated, negatively correlated and positively correlated E-modulus and $\mathrm{r}$ are shown in Fig. 5d-f. Unfortunately, there is no sound basis for choosing any kind of this correlation. International Journal of Solids and Structures 2006. 43, 435-458.

As for the status of themes, the results reported in Table 2 below indicate that in the corpus of all disciplines the unmarked themes outnumbered the marked themes. 
Table 2

Adjusted frequencies of unmarked and marked themes in the RAs (per $10000 \mathrm{~T}$ units)

\begin{tabular}{lcc}
\hline & \multicolumn{2}{c}{ Theme status } \\
\hline Mechanical engineering & Unmarked & Marked \\
\hline Biomedical engineering & 6800.43 & 3199.56 \\
\hline Horticulture & 7537.68 & 2462.31 \\
\hline Environmental science & 7647.11 & 2352.88 \\
\hline
\end{tabular}

Yet, testing the first hypothesis of the study by running a chi-square test (Tables 3 $\& 4$ ), we found out that there is a significant difference in the Theme status between the well-established disciplines of mechanical engineering and horticulture and the emerging disciplines of biomedical engineering and environmental science. In both groups of well-established and emerging disciplines the unmarked themes were far more prevalent, but comparatively speaking in the RAs of the former group marked themes were more frequent. 
Table 3

Distributions of unmarked and marked themes in the RAs of well-established and emerging disciplines

\begin{tabular}{lllrrr}
\hline & & \multicolumn{2}{c}{ Theme status } & \\
\cline { 3 - 5 } Disciplines & Emerging & Count & Unmarked & Marked & \multicolumn{1}{c}{ Total } \\
\cline { 3 - 5 } & Expected Count & 7380.0 & 2620.0 & 10000.0 \\
\cline { 2 - 5 } & Well-established & Count & 7138 & 2862 & 10000 \\
& & Expected Count & 7380.0 & 2620.0 & 10000.0 \\
\hline Total & Count & 14760 & 5240 & 20000 \\
& & Expected Count & 14760.0 & 5240.0 & 20000.0 \\
\hline
\end{tabular}

Table 4

Chi-square test of theme status in the RAs of well-established and emerging disciplines

\begin{tabular}{lccr}
\hline & Value & Df & Asymp. Sig. (2-sided) \\
\hline Pearson Chi-Square & 60.576 & 1 & .000 \\
Likelihood Ratio & 60.643 & 1 & .000 \\
\hline Linear-by-Linear Association & 60.573 & 1 & .000 \\
\hline N of Valid Cases & 20000 & & \\
\hline
\end{tabular}

In the first phase of the study the composition of themes, that is, the occurrence of textual and interpersonal themes, was also examined. 
Table 5

Adjusted frequencies of simple and multiple themes in the RAs (per 10000 T-units)

\begin{tabular}{lcc}
\hline & \multicolumn{2}{c}{ Theme composition } \\
\hline & Simple & Multiple \\
\hline Mechanical engineering & 7974.55 & 2025.44 \\
\hline Biomedical engineering & 8138.26 & 1861.73 \\
& & \\
\hline Horticulture & 8080.56 & 1919.43 \\
\hline Environmental science & 8107.59 & 1892.4 \\
\hline
\end{tabular}

As is displayed in Table 5, in the RAs of both well-established and emerging disciplines simple themes were far more frequent than multiple themes. The results of a chi-square test for testing the related hypothesis are set out in Tables 6 and 7 below. As the $\mathrm{p}$ value is .058 which is larger than .05 , the null hypothesis in not rejected and we conclude that there is no significant difference in the Theme composition between the well-established disciplines of mechanical engineering and horticulture and the emerging disciplines of biomedical engineering and environmental science.

Table 6

Distributions of simple and multiple themes in the RAs of well-established and emerging disciplines

\begin{tabular}{lllrrr}
\hline & & \multicolumn{2}{c}{ Theme composition } & \\
\cline { 3 - 4 } Disciplines & Emerging & Count & 8123 & 1877 & 10000 \\
& & Expected Count & 8070.0 & 1930.0 & 10000.0 \\
\cline { 3 - 5 } & Well-established & Count & 8017 & 1983 & 10000 \\
& & Expected Count & 8070.0 & 1930.0 & 10000.0 \\
\hline Total & Count & 16140 & 3860 & 20000 \\
& & Expected Count & 16140.0 & 3860.0 & 20000.0 \\
\hline
\end{tabular}


Table 7

Chi-square test of theme composition in the RAs of well-established and emerging disciplines

\begin{tabular}{lccc}
\hline & Value & df & \multicolumn{2}{c}{$\begin{array}{c}\text { Asymp. Sig. (2- } \\
\text { sided) }\end{array}$} \\
\hline $\begin{array}{lccc}\text { Pearson Chi-Square } \\
\text { Likelihood Ratio }\end{array}$ & 3.607 & 1 & .058 \\
\hline Linear-by-Linear & 3.607 & 1 & .058 \\
Association & 3.607 & 1 & .058 \\
\hline N of Valid Cases & & & \\
\hline
\end{tabular}

In addition to comparing the frequency of simple and multiple themes, the content of the multiple themes were examined more closely. The results, reported in Table 8 , indicate that in bothemerging and well-established disciplines the textual themes outnumbered the interpersonal themes by a large margin, and the authors showed the least preference to the use of the combination of textual and interpersonal themes.

Table 8

Distributions of different types of multiple themes in the RAs of wellestablished and emerging disciplines

\begin{tabular}{lrrrrrr}
\hline & & \multicolumn{5}{c}{ Multiple themes } \\
\hline & & Textual & Interpersonal & $\begin{array}{c}\text { Textual + } \\
\text { Interpersonal }\end{array}$ \\
\hline & F & $\%$ & F & $\%$ & F & $\%$ \\
\hline $\begin{array}{l}\text { Emerging } \\
\text { disciplines }\end{array}$ & 4310 & $\mathbf{9 2 . 2 9}$ & 315 & $\mathbf{6 . 7 4}$ & 45 & .97 \\
\hline $\begin{array}{l}\text { Well-established } \\
\text { disciplines }\end{array}$ & 4690 & $\mathbf{9 0 . 0 8}$ & 460 & $\mathbf{8 . 8 4}$ & 56 & $\mathbf{1 . 0 8}$ \\
\hline
\end{tabular}




\subsection{Patterns of Thematic Progression}

Having analyzed the themes and rhemes of the RAs, in the second phase of the study, we tried to identify the patterns of thematic progression in the texts based on McCabe's (1999) model of thematic progression. We started with McCabe's model but as we proceeded we noticed that a modified version of Constant Theme progression is frequently used in the RAs and if we do not take it into account in our analysis we cannot present a real picture of TP patterns in the RAs. This modified version which is also suggested by Hawes and Thomas (1997) is called Constant Theme plus Gap progression or Constant Gap progression (Hawes, 2015). In this pattern, one or more non-related T-units come between T-units with constant themes. The pattern is 'less heavy' than the constant theme progression (Hawes, 2015).

EXAMPLE 4: The AMF inoculation did not alter the JA content with respect to control plants. AMF-T. harzianum co-inoculated plants showed a decrease in comparison with plants inoculated with only $\mathrm{T}$. harzianum and had a JA content similar to that of uninoculated control plants (Fig. 3A). The SA content was increased (by $75 \%$ ) in $\mathrm{T}$. harzianuminoculated plants relative to uninoculated control plants $(\mathrm{P}<0.001)$ (Fig. 3B). The AMF inoculation did not change the SA content with respect to the uninoculated plants. AMF-T. harzianum co-inoculated plants showed an increased SA content compared with plants inoculated only with the AMF whereas the content was decreased in comparison with plants inoculated only with T. harzianum. Phytochemistry 2011, 72, 223-229.

Furthermore, we found a new pattern while analyzing the RAs. In the new pattern, which is in fact the opposite of the split theme pattern, the themes of two or more adjacent $\mathrm{T}$-units join together in the theme of the subsequent $\mathrm{T}$-unit. We call it the Convergent Theme progression pattern. An example from the corpus is as follows: 
EXAMPLE 5: A thin sheet of elastomer is first prestretched, crossed-wire electrodes are then attached to the two surfaces of the elastomer, and both the elastomer and the electrodes are embedded in a stiff polymer. Journal of Mechanics and Physics of Solids, 2015, 76, 47-64.

All in all, here the results of TP analysis in the second phase of the study are presented in six patterns of thematic progression.

As regards the mechanical engineering RAs, of 15799 T-units, 7122 T-units were in the thematic progression chains and the remaining 8677 T-units (i.e. 54.92 percent of the T-units) were peripheral themes. Among the former, 849 T-units (5.37 percent) were involved in more than one thematic pattern. Out of $12671 \mathrm{~T}$ units in the biomedical engineering RAs, 6988 T-units formed the six types of thematic chains and $5683 \mathrm{~T}$-units (that is, 44.85 percent of the T-units) were peripheral themes. $773 \mathrm{~T}$-units of the former group (6.1 percent) were parts of more than one thematic progression pattern. In the horticulture RAs, of all 10451 T-units, 6141 T-units formed thematic chains and the rest, 4310 T-units (41.24 percent), were peripheral themes. Also, 691 T-units (6.61 percent) were counted more than once. Finally, in the environmental science RAs, out of 12212 T-units, 6478 T-units were in thematic patterns and 959 (7.85 percent) of them were in more than one chain. 5734 T-units (46.95 percent) did not form any thematic pattern.

Now to see how the six types of thematic progression patterns were distributed in the RAs of the four disciplines, the results are presented in Table 9. 
Table 9

Adjusted frequencies of the thematic progression patterns in the RAs (per $1000 \mathrm{~T}$ units)

\begin{tabular}{lllllll}
\hline & $\begin{array}{l}\text { Simple } \\
\text { linear }\end{array}$ & $\begin{array}{l}\text { Constant } \\
\text { theme }\end{array}$ & $\begin{array}{l}\text { Constant } \\
\text { theme gap }\end{array}$ & $\begin{array}{l}\text { Split } \\
\text { rheme }\end{array}$ & $\begin{array}{l}\text { Split } \\
\text { them } \\
\text { e }\end{array}$ & $\begin{array}{l}\text { Convergent } \\
\text { theme }\end{array}$ \\
\hline $\begin{array}{l}\text { Mechanical } \\
\text { engineering }\end{array}$ & 599.46 & 286.96 & 43.62 & 29.53 & 38.03 & 2.40 \\
\hline $\begin{array}{l}\text { Biomedical } \\
\text { engineering }\end{array}$ & 463.22 & 377.17 & 63.68 & 50.17 & 40.56 & 5.20 \\
\hline Horticulture & 463.73 & 401.40 & 35.15 & 43.15 & 53.70 & 2.87 \\
\hline $\begin{array}{l}\text { Environmental } \\
\text { science }\end{array}$ & 472.57 & 380.96 & 55.13 & 44.84 & 44.27 & 2.23 \\
\hline
\end{tabular}

As the Table shows, in the RAs of both well-established and emerging disciplines, the two thematic progression patterns of simple linear and constant theme were the most prevalent while the convergent theme progression was the least common pattern. Yet, to see if there was any significant difference between the distributions of the patterns in the two groups of disciplines, a chi-square was run. Its results, presented in Tables 10 and 11, revealed that there is a significant difference in the thematic progression patterns between the well-established disciplines of mechanical engineering and horticulture and the emerging disciplines of biomedical engineering and environmental science. More specifically, while in both groups of disciplines, the simple linear pattern was the most observed progression, comparatively speaking in the emerging disciplines the difference between the occurrences of the simple linear and constant theme patterns was smaller and in fact the latter pattern was used more commonly. 
Tables 10

Thematic progression patterns in the RAs of well-established and emerging disciplines

\begin{tabular}{|c|c|c|c|c|c|}
\hline & & & \multicolumn{2}{|c|}{ Disciplines } & \multirow[b]{2}{*}{ Total } \\
\hline & & & Emerging & $\begin{array}{c}\text { Well- } \\
\text { established }\end{array}$ & \\
\hline \multirow{12}{*}{$\begin{array}{l}\text { Patter } \\
\text { ns }\end{array}$} & \multirow[t]{2}{*}{ Simple linear } & Count & 4677 & 5378 & 10055 \\
\hline & & $\begin{array}{l}\text { Expected } \\
\text { Count }\end{array}$ & 5028.0 & 5027.0 & 10055.0 \\
\hline & \multirow{2}{*}{$\begin{array}{l}\text { Constant } \\
\text { theme }\end{array}$} & Count & 3790 & 3389 & 7179 \\
\hline & & $\begin{array}{l}\text { Expected } \\
\text { Count }\end{array}$ & 3589.9 & 3589.1 & 7179.0 \\
\hline & \multirow{2}{*}{$\begin{array}{l}\text { Constant } \\
\text { theme gap }\end{array}$} & Count & 596 & 398 & 994 \\
\hline & & $\begin{array}{l}\text { Expected } \\
\text { Count }\end{array}$ & 497.0 & 497.0 & 994.0 \\
\hline & \multirow[t]{2}{*}{ Split rheme } & Count & 476 & 357 & 833 \\
\hline & & $\begin{array}{l}\text { Expected } \\
\text { Count }\end{array}$ & 416.5 & 416.5 & 833.0 \\
\hline & \multirow[t]{2}{*}{ Split theme } & Count & 424 & 451 & 875 \\
\hline & & $\begin{array}{l}\text { Expected } \\
\text { Count }\end{array}$ & 437.5 & 437.5 & 875.0 \\
\hline & \multirow{2}{*}{$\begin{array}{l}\text { Convergent } \\
\text { theme }\end{array}$} & Count & 38 & 26 & 64 \\
\hline & & $\begin{array}{l}\text { Expected } \\
\text { Count }\end{array}$ & 32.0 & 32.0 & 64.0 \\
\hline \multirow[t]{2}{*}{ Total } & & Count & 10001 & 9999 & 20000 \\
\hline & & $\begin{array}{l}\text { Expected } \\
\text { Count }\end{array}$ & 10001.0 & 9999.0 & 20000.0 \\
\hline
\end{tabular}


Table 11

Chi-square test of thematic progression patterns in the RAs of wellestablished and emerging disciplines

\begin{tabular}{lccr}
\hline & Value & df & Asymp. Sig. (2-sided) \\
\hline Pearson Chi-Square & 130.794 & 5 & .000 \\
Likelihood Ratio & 131.182 & 5 & .000 \\
Linear-by-Linear Association & 54.793 & 1 & .000 \\
\hline N of Valid Cases & 20000 & & \\
\hline
\end{tabular}

\section{Discussion}

The findings of the present study provide a picture of Theme selection in the RAs of four disciplines and confirm the typicality of certain thematic choices like simple themes and unmarked themes. The findings also shed light on the thematic profile of the genre of research article. It was found out that in the RAs of all four disciplines studied in this research, subject, adjunct, and dependent clauses were the most frequently used Themes while thematic equative and predicated Themes were the least frequent Themes. The subject being the most frequently used Theme in the whole corpus confirms the point about the conflation of Theme and Subject as the typical pattern of declarative clauses (Halliday, 1994; Halliday \& Matthiessen, 2004). It should be also pointed out that although subordinate clauses were the third most frequent themes in the corpus, they were vastly outnumbered by subjects and adjuncts and formed a small percent of themes in the RAs of four disciplines. This echoes the findings of Lovejoy (1991) that in the fields with complicated subject matters writers do not use a very large number of subordinate 
clauses as Theme in order to use technical vocabulary in structurally simple sentences to achieve high readability.

Another finding of this research is that in all four disciplines the number of textual themes was far larger than the number of interpersonal themes and the textual + interpersonal themes were used very infrequently. This is compatible with the findings of some other studies on the RAs of other disciplines like Whittaker (1995) as well as Khany \& MansooriNejad (2010). The role of textual themes in creating coherent texts is vital (Vande Kopple, 1991) and based on some studies using them frequently and widely is a sign of effective academic writing (Mellos, 2011). In each of the following excerpts of a mechanical engineering article and a biomedical engineering paper, three textual themes are appropriately used in four succeeding T-units.

The low proportion of interpersonal themes can reflect high levels of impersonality (Martı'nez, 2003) and "authority and distance" (Eggins, 2004, p. 322 ) in the sciences to stress "objectivity, open-mindedness, and the established factual nature of a given activity" and the "common share of knowledge with the community" (Lachowicz, 1981, p. 111, as cited in Hyland, 2001).

As regards thematic progression patterns, in this study a new thematic progression pattern was identified in the corpus. We named it the convergent theme. By finding new patterns, we can develop and modify the existing models and have a more comprehensive picture of cohesion in discourse. With regard to the distribution of patterns, we found out that in the four corpora of RAs the linear progression pattern and the constant theme pattern vastly predominated. This is entirely consistent with the results of Khany \& MansooriNejad 's (2010) study on applied linguistics RAs and partly with Nwogu (1997) who found out that the constant pattern was the dominant pattern in a sample of medical research articles. 
EXAMPLE 7: Bland-Altman plots illustrated a randomly distributed scatter across strain magnitudes for Eqs. (i) and (iii) (Fig. 5). In contrast, Eq. (ii) illustrated systematic scatter in which strains were underpredicted at high strain magnitudes and over-predicted at low strain magnitudes. Overall, predicted strains using the Eq. (i) were most closely matched to measured strains in terms of regression coefficients, error, and scatter. Therefore, the finite element models created using Eq. (i) were used for failure analyses. Medical Engineering \& Physics 2012, 34, 290-298.

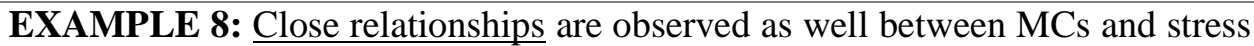
indices, such as SOD activity (+) and soluble protein (_), suggesting that both $\mathrm{NHp} 4$ and MCs affect the normal growth and metabolism of major aquatic plants in Lake Taihu. Among these relationships, both NHp4 -to-C-N reserves and MCs-to-oxidative stress are most remarkable. $\underline{\text { In addition to these }}$ relationships, the SOD activities in these plants are closely related to water temperature (+), DO (_), Microcystis biomass (+), and cyanobacteria biomass $(+)$, rather than with NHp4 in Meiliang Bay.

Constant Theme Pattern

Chemosphere 2011, 82, 329-339.

EXAMPLE 9: Along with the wave speed distribution, it is assumed that crystal orientation-dependent strain hardening, and reflection and refraction of waves at grain boundaries will give rise to particle velocity fluctuations. Velocity fluctuations indicate that for a macroscopic planar impact it is possible to realise a non-laminar flow. Velocity fluctuations have been shown to influence macroscopic properties such as dynamic shear and spall strength.

Simple Linear \& Constant Theme Patterns

Journal of the Mechanics and Physics of Solids 2007, 55, 589-614.

The mentioned commonalities among the RAs of four disciplines can be partly explained with reference to the genre itself as the theme-rheme analysis, including both thematic choices and thematic patterns, can be a means of genre identification 
helpful for both finding distinguishing features among genres and establishing the features of a genre (Eiler, 1986; Francis, 1989; McCabe, 1999; Vande Kopple, 1991). So, up to this point based on the findings of this study we can suggest that the high frequency of unmarked themes which lead to topic continuity (Martı'nez, 2003) is the typical feature of RAs, writers of RAs favor textual themes for creating cohesion and coherence over interpersonal themes for interacting with the readers, and they use the two thematic patterns of simple linear and constant theme frequently for creating cohesion plus topical focus and creating persuasion.

In addition to the mentioned common features of the RAs of the four disciplines, some results of this study showed that there are aspects of thematicity that vary across the sampled disciplines with regard to the status of disciplines. With respect to the theme status, in both groups of disciplines the unmarked themes outnumbered the marked themes, but in comparison authors in the well-established disciplines used more marked themes. It seems that as the well-established disciplines have well-established theories and a stronger theoretical ground, the authors, who have access to a long tradition of academic writing in their disciplines, are more confident to complicate the language and use marked themes strategically and skillfully by building on that ground. But, the writers in the emerging disciplines still have to deal with conceptual and methodological clarifications in their writings, and thus engage less actively in making the language complex.

This is also reflected in the use of existential clauses. While in both groups of disciplines positive existential clauses were used more frequently than the negative clauses, in comparison in the well-established disciplines the writers used far more negative there clauses. In fact, the researchers in the emerging disciples were mainly concerned with presenting information than with responding to readers' expectations. In the same vein, comparing the theme categories, we found out that the number of wh-questions, with the wh-word as the Theme, was very larger in the less well-established disciplines than in the well-established disciplines. In fact, the wh-word plus thematic equatives and predicated theme were the least frequent Themes categories in the well-established disciplines while in the less wellestablished fields, complements replaced the first one. These findings can support 
our understanding of the reasoning behind differences in using marked and unmarked themes in the well-established and emerging disciplines. In the emerging disciplines, the writers may use more wh-questions to clarify the focus of research, but the authors in the well-established fields are more competent to use complements, one of the highly marked kinds of theme. Finally, a concern for the language and its structuring is reflected in the more common use of the simple linear pattern in the RAs of the well-established disciplines to create cohesion and coherence in the texts. As mentioned before, the writers in both groups of disciplines used the simple linear and constant theme patterns more frequently, but in the well-established disciplines the former was still far more common.

\section{Conclusion}

This study investigated thematic choices in the RAs of four disciplines. The findings can complete our understanding of the discursive features of RA as a genre. Furthermore, as we specially focused on the potential influences of the disciplines' status on thematic choices, the results can serve the disciplinary research and are relevant to the characterization of the language of science in disciplines as the established units of scientific work. Different disciplinary communities are contexts with a variety of features, with some being more overt than the others, which do not treat a genre exactly like each other as authors reflect their explicit and/or implicit awareness of the discursive norms of their academic communities in their writings. The status of disciplines, as one of these features, has not been investigated as a significant factor in discourse studies. Given the findings of this study about this factor in relation to thematic choices and thematic patterns in RAs, we suggest that the status and establishment of disciplines deserves more attention in discourse studies and further research into it in different disciplinary analyses of the theme-rheme construct would go farther in providing valuable insights. Future studies may focus on other disciplines, especially underresearched and nascent disciplines, to complement the preliminary findings of this study and provide more comprehensive descriptions. 


\section{References}

Ammon, U. (2001). Editor's preface. In U. Ammon (Ed.), The dominance of English as a language of science (pp. v-x). Berlin, Germany: Mouton de Gruyter.

Aktas, R. N., \& Cortes, V. (2008). Shell nouns as cohesive devices in published and ESL student writing. Journal of English for Academic Purposes, 7, 314.

Avison, D. A. (1997). The Search for the 'Discipline' of Information Systems. In G. McKenzie, J. Powell \& R. Usher (Eds.), Understanding Social Research: Perspectives on Methodology and Practice (pp 83-95). London: Palmer Press.

Bachman, L. (1990). Fundamental Considerations in Language Testing. London: Longman.

Bhatia, V. K. (2004). Worlds of written discourse: A genre-based view. London: Continuum.

Biglan, A. (1973). The Characteristics of Subject Matters in Different Academic Areas. Journal of Applied Psychology, 57, 195-203.

Brandt, D. (1986). Text and context: How writers come to mean. In B. Couture (Ed.), Functional approaches to writing, research perspectives (pp. 93107). Norwood, NJ: Ablex.

Burgess, S. (2002). Packed houses and intimate gatherings: Audience and rhetorical structure. In J. Flowerdew (Ed.), Academic discourse (pp. 196215). London: Longman/Pearson Education.

Canagarajah, A. S. (2002). Critical academic writing and multilingual students. Ann Arbor: University of Michigan Press.

Cargill, M., \& O'Connor, P. (2009). Writing scientific research articles. West Sussex: Wiley- Blackwell.

Connor, U. (1984). A study of cohesion and coherence in English as a second language student's writing. Papers in Linguistics, 17, 301-316.

Curry, M. J., \& Lillis, Th. (2010). Academic research networks: Accessing resources for English-medium publishing. English for Specific Purposes, 29, 281-295. 
Duszak, A. (1997). Culture and styles of academic discourse. Berlin, Germany: Mouton de Gruyter.

Eggins, S. (2004). An Introduction to Systemic Functional Linguistics. London: Continuum.

Eiler, M. (1986). Thematic distribution as a heuristic for written discourse function. In B. Couture (Ed.), Functional Approaches to Writing, Research Perspectives (pp. 49-68). Norwood, New Jersey: Ablex.

Ferenz, O. (2005). EFL writers' social networks: Impact on advanced academic literacy development. Journal of English for Academic Purposes, 4, 339351.

Flowerdew, J. (2001). Attitudes of journal editors to nonnative speaker contributions. TESOL Quarterly, 35(1), 121-150.

Francis, G. (1989). Thematic Selection and Distribution in Written Discourse. Word, 40(1-2), 201-222.

Fries, P. H. (1994). On Theme, Rheme and Discourse Goals. In M. Coulthard (Ed.), Advances in Written Text Analysis (pp. 229-249).London and New York: Routledge.

Fries, P. H. (1995). A personal view of theme. InM. Ghadessy (Ed.), Thematic development in English texts (pp. 1-19). London: Pinter.

Fries, P. H., \& Francis, G. (1992). Exploring Theme: Problems for Research. Occasional Papers in Systemic Linguistics, 6, 45-59.

Geisler, C. (1994). Academic literacy and the nature of expertise: Reading, writing and knowing in academic philosophy. Hillsdale, NJ: Erlbaum.

Gonzalez, W. J. (2013). From the sciences that Philosophy has "neglected" to the new challenges. In H. Andersen, D. Dieks, W. J. Gonzalez, T. Uebel, \& G. Wheeler (Eds.), New challenges to philosophy of science (pp. 1-7). Dordrecht: Springer.

Greaves, S. (2008). Strategic Security as a New Academic Discipline. Journal of Strategic security, 1(1), 7-19.

Halliday, M. A. K. (1985/1994). An introduction to functional grammar. London: Edward Arnold. 
Halliday, M. A. K. (1993). On the language of physical science. In M. A. K. Halliday \& J. R. Martin (Eds.), Writing science: Literacy and discursive power (pp. 54-68). London: The Falmer Press.

Halliday, M. A. K., \&Matthiessen, Ch. M. I. M. (2004). AnIntroduction to Functional Grammar. London: Hodder Arnold.

Hawes, Th., \& Thomas, S. (1997). Problems of thematisation in student writing.RELC Journal, 28(2), 35-55.

Hawes, T. (2015). Thematic progression in the writing of students and professionals. Ampersand, 2, 93-100.

Hinkel, E. (2001). Matters of cohesion in L2 academic texts. Applied Language Learning, 12, 111132.

Hyland, K. (2001). Humble servants of the discipline? Self-mention in research articles. English for specific purposes, 20(3), 207-226.

Khany, R., \&MansooriNejad, A. (2010). The interaction between rhetorical structure and thematisation in academic research articles. IJAL, 13(1), 4772 .

Lachowicz, D. (1981). On the use of the passive voice for objectivity, author responsibility and hedging in EST. Science of Science, 2(6), 105-115.

Lei, L. (2012). Linking adverbials in academic writing on applied linguistics by Chinese doctoral students. Journal of English for Academic Purposes, 11, 267-275.

Lillis, Th., \& Curry, M. J. (2006). Professional academic writing by multilingual scholars: Interactions with literacy brokers in the production of Englishmedium texts. Written Communication, 23(1), 3-35.

Lovejoy, K. B. (1991). Cohesion and information strategies in academic writing: Analysis of passages in three disciplines. Linguistics and Education, 3, 315-43.

Martinez, I. A. (2003). Aspects of theme in the method and discussion sections of biology journal articles in English. Journal of English for Academic Purposes, 2, 103-123.

McCabe, A. (1999). Theme and Thematic Patterns in Spanish and English History Text (PhD Dissertation). Aston: Aston University. 
Mellos, V. D. (2011). Coherence in English as a second language undergraduate writing: a theme-rheme analysis (Unpublished Master's Thesis). San Diego State University.

Nesi, H., \&Basturkmen, H. (2006). Lexical bundles and discourse signaling in academic lectures. International Journal of Corpus Linguistics, 11, 147168.

North, S. (2005). Disciplinary Variation in the Use of Theme in Undergraduate Essays. Applied Linguistics, 26(3), 431-452.

Nwogu, K. N. (1997). The medical research paper: Structure and functions, English for Specific Purposes, 16(2), 119-138.

Peters, S. (2011). Asserting or deflecting expertise? Exploring the rhetorical practices of master's theses in the philosophy of education. English for Specific Purposes, 30, 176-185.

Plum, G. (1988). Textual and contextual conditioning in spoken English: a genrebased approach (Unpublished $\mathrm{PhD}$ Dissertation). Department of Linguistics, University of Sydney.

Polo, F. J., \& Varela, M. C. (2009). English for research purposes at the University of Santiago de Compostela: A survey. Journal of English for Academic Purposes, 8, 152-164.

Strohmayer, U. (2014). Historical Geographical Traditions. In J. Morrissey, D. Nally, U. Strohmayer, \&Y. Whelan (Eds.), Key Concepts in Historical Geography (pp. 269-279). London: Sage.

Tardy, Ch. M. (2005). "It's like a story": Rhetorical knowledge development in advanced academic literacy. Journal of English for Academic Purposes, 4, 325-338.

Thompson, G. (2004). IntroducingFunctional Grammar. London: Arnold

Thornbury, S. (1999). How to Teach Grammar. Essex: Pearson Education Limited.

Trench, B., \& Bucchi, M. (2010). Science communication, an emerging discipline. JCom, 9(3).

Uzuner, S. (2008). Multilingual scholars' participation in core/global academic communities: A literature review. Journal of English for Academic Purposes, 7(4), 250-263. 
VandeKopple, W. J. (1991). Themes, thematic progressions, and some implications for understanding discourse. Written Communication, 8(3), 311-347.

Webster, G. D. (2012). Quantitative Trends in establishing a psychology of science: A review of the metasciences. In G. J. Feist\& M. E. Gorman, (Eds.), Handbook of the psychology of science (pp. 487-506). Springer.

Whittaker, R. (1995). Theme, processes and the realization of meanings in academic articles. In M. Ghadessy (Ed.), Thematic development in English texts (pp. 105-128). London: Pinter.

\section{Notes on Contributors:}

Esmat Babaii is Associate professor of applied linguistics at Kharazmi University, Iran, where she teaches research methods, language assessment and discourse analysis to graduate students. She has served on the editorial boards and/or the review panels of several national and international journals. She has published articles and book chapters dealing with issues in Systemic Functional Linguistics, Appraisal theory, test-taking processes, English for Academic Purposes, and critical approaches to the study of culture and language. Her most recent work is a co-authored paper on social semiotic analysis of social actors in English learning software (2017).

Mahmood Reza Atai is professor of applied linguistics at Kharazmi University, Tehran, Iran. He has taught ESP, materials development and ELT in Iran and the world to PHD students. Also he has served as editorial board member in several international and national journals. He has published extensively on ESP/EAP themes including needs analysis, genre analysis and teacher education.

Leila Shoja is currently a Ph.D. student of applied linguistics at Kharazmi University, Iran. Her research interest areas include discourse analysis, English for specific purposes, and materials development. Her last paper was on needs analysis for EAP courses in Iran, and she has co-authored an EAP book for the students of medicine. 